\title{
THE IMPACT OF RURAL TOURIST RECREATIONAL SPACE DESIGN ON TOURISM DEVELOPMENT AND TOURIST ATTRACTION IN IRAN
}

\author{
Kianoosh Yousefi \\ Master Of Architecture, Islamic Azad University, Kerman Branch
}

\begin{abstract}
Rural development and thus, country development is a multi-dimensional process which its subject is improving the quality of life of the vulnerable villagers. One of the development dimensions which can have the overall impact on people's lives is the expansion of tourism. Rural tourism is considered as a process in rural development which can evolve village economy and environment by creating complementary activities and thus, leads to improve the quality of life and a balanced and proportional distribution of services and facilities. If rural tourism be done planned and purposeful, it can be protected from injuries which tourist causes. One way of making this process purposeful is creating specific spaces with capability of transform into recreational spaces. Centralizing tourist recreational services providing with the goal of creating an appropriate service atmosphere causes maintaining order and control of the environment and creating ecological balance. In this article, we are going to learn about importance of designing these spaces in villages and its role in the development of the national tourism industry.
\end{abstract}

Keywords: tourism development, rural tourist recreational spaces, rural development, tourism

\section{INTRODUCTION}

Villages were created in response to human settlement and formation of first bio complexes. The creation of common goals caused a kind of attachment and affection and common interests between residents and this is one of the factors which was considered as texture development of the village. A common behavior among residents was created seeks to create common ground of human that led to create similar spaces in the name of housing with common features, after providing basic human needs, it was subpoenaed from individual environment and isolationism to the social environment and the scene of actions and social interactions of people was developed and spaces for mass communication was created. The sum of individual and collective created spaces in each village is so called village texture, that this texture has value and social, climatic, cultural and artistic features of residents.

Iran has a wide range of diversity in rural contexts according to the vast existing expanse and five climatic zones and the creation of different ethnic groups with different cultures. Despite the rich elements of architecture and landscape architecture, the village which are not few in the country, for various reasons, caused a degree of wear and tear on their body and activity and the spirit of life in them is gradually being destroyed.

Lack of basic amenities of living, poverty and lack of sustainable employment opportunities and thus, being under the damage of economic situation of households have led to the gradual evacuation of the inhabitants of such places. While these valuable rural textures can become amenable and pleasant for tourists and leisure, they are being converted to ruins of residential buildings which will be forgotten because of the destruction of important architectural and natural elements of different parts of Iran.

Sustainable tourism development is the best solution to prevent physical deterioration and social and economic life of such environments. Such development plays an effective role in the revitalization of the textures by approach of a tourist attraction while preserving natural resources and natural landscape and creating tourist recreational space with minimal manipulation of the natural environment, thus will result 
in poverty alleviation, reduction of immigration, creating social welfare, preservation of traditional valuable textures, cultural revitalization and globalization of the village as well as agricultural activities.

\section{RESEARCH METHOD}

The research method in this study is analytical, descriptive and interpretive. The main part of used data is obtained through observational method in form of field studies and partly through library research.

\section{CONCEPTS}

Development and tourism development:

Discover ways to achieve evolutionary movement is considered as development, which balances social, economic and cultural phenomena and provides new conditions for social, economic mobility and realization of social justice (Zahedi Asl 5: 1381).

Accordingly, benefit people is known as the basic objective of development, which encompasses improving the quality of life and appears in the form of incomes rising and expanding of employment and general welfare (Griffin and Mac Kennelly, 11: 1375) Hence the concept of human development and sustainable development, will have binding relation which needs to standardize and synchronize with each other and in this way, taking advantage of social capital and social participation is important.

Accordingly, the development must be shaped in the form of the identity of each nation, which a collection of idea reserves existed in the identity construction is used to accelerate the development process. The concept of development has both quantitative and qualitative dimensions and the economic aspect is considered as quantitative dimension which points out economic growth that monitors the slow and gradual changes in the savings rate and improve national per capita income and GDP and according to "Leberger", it is productivity growth without being changed in the manner and in the production organization and "Friedmann" also considers it as expanding system in different directions without changing the infrastructure (Zahedi Asl, 9: 1381).

The development basic objective may be considered as the qualitative dimension of development, which a means called social security is needed to achieve it, to allow movement to achieve social welfare, accordingly, social welfare indicators can be considered as economic, family, health, nutrition conditions and the field of collective life (Mohseni, 1382) education, healthcare \& employment, housing and leisure (Zahedi Asl, 1381).

\section{Rural Development:}

It is the process of empowering and strengthening the ability of life in the context of life and environmental quality, performance, economic self-sufficiency and maintenance and improvement of environmental quality in rural areas (2003: 7, Holand).

The development is assumed as positive changes which involve improving lives of the people (Zamani Pur, 40: 1373). Sizer considers development as the multidimensional flow which is followed by different reorganization and orientation of whole economic and social system and in many cases, it encompasses customs and beliefs of the people (Abedi sarvestani 138: 1385).

In third world countries, two visions have been considered in the field of rural development.

First: vision of improving and modifying and second: vision of transforming (Seyed Javad Mir, 1371Azkia, 1374 - Ashurani, 1375).

Since tourism is considered as a process in rural development, the evaluation component of tourism should be specially referred to within the framework of rural development as a management position and 
attempted to provide the possibility of evaluating process of rural tourism and, if necessary, its continuity by identifying objectives and environmental impacts of tourism.

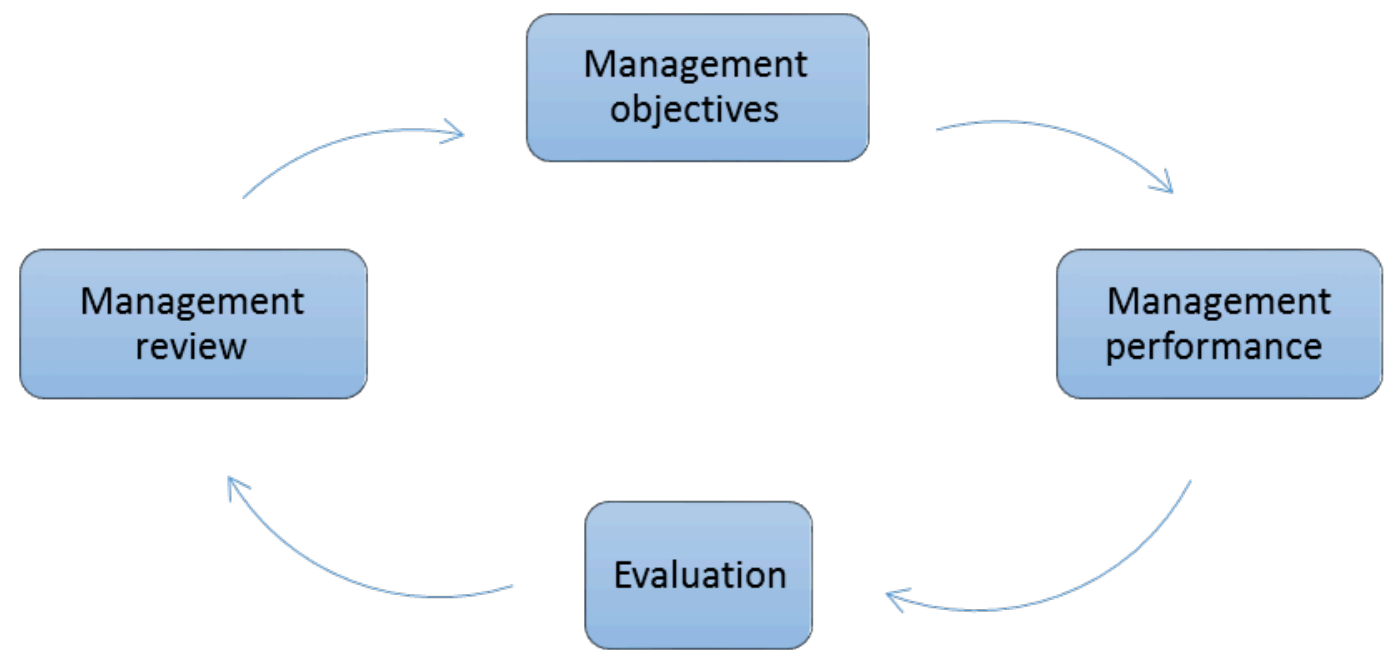

Figure 1: Results of environmental studies (Sources: Mahmudinezhad (1387))

The position of tourism in rural development:

Since rural development is not only focused on agricultural development (Mira, 11: 1365), opportunities can be considered for more efficiency of rural development. In the meantime, rural tourism should be considered as an approach towards rural empowerment to have sustainable livelihoods and life quality improvement in the context of a special focus on agricultural development as one of the vital activities of human life. Accordingly, tourism is considered as the new approach in rural development, which in addition to economic recovery and growth, it provides protection possibility of rural environment together with support from indigenous culture and strengthen the local social customs. Based on this, it can be realized that the position of rural tourism should be studied by evaluating the economic, social and environmental characteristics. Meanwhile, paying attention to the procedure of sustainable development and correspondence between rural tourism purposes and rural development seems necessary.

Rural tourism:

Currently, as a sector of the market and one of the most popular tourist types, rural tourism has been paid attention to by many tourists. As a destination, the tourism sector has its own customers and has been growing day by day and attracts more customers. What will attract tourists to rural areas is varied and includes a range from absolute silence and tranquility of nature to religious and historical attractions and other types of attractions which can be found in cities.

In general, according to the concept of rural tourism, it can be said "multifaceted activity which takes place outside of the city and shows tourists the essence of rural life " (Graham Dann, 1999). Or all tourism activities in the rural environment according to traditional texture and culture, art and rural industries, traditional customs which include agricultural tourism, green tourism, farm tourism, food tourism and hunting (Ghaderi, 1383). 


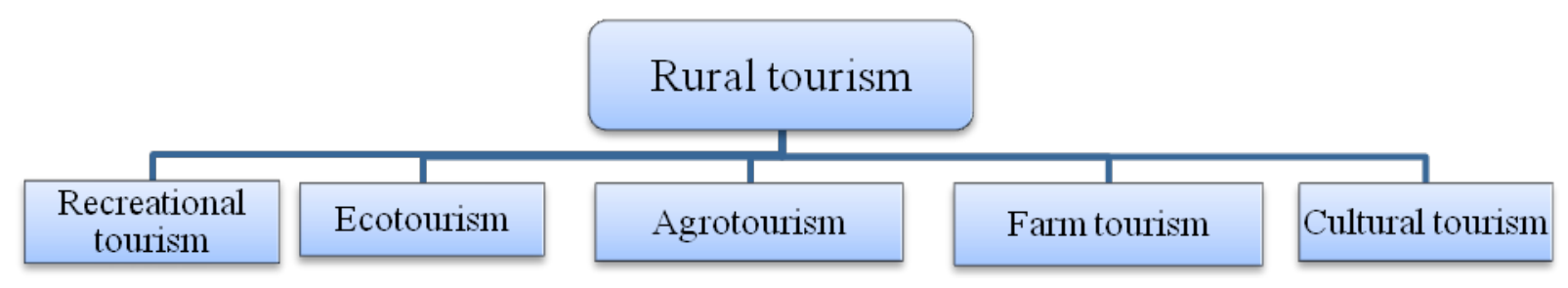

Figure 2: Typology of rural tourism

Rural tourism has different samples that illustrate complex pattern of environment, economy, history and village location (Lin 1994). Nature and rural environment and historical and cultural heritage are main requirements of tourism development, because these factors play important role in attracting tourists and rural life in last decade and due to increased tourism. So it can be said that rural tourism includes tourism activities in various fields that are shown in Figure 2.

It can be said that if natural attractions of villages such as clean air and nature are incentives of travelling to village it will be recreational tourism; if the aim is to visit regional and agricultural production it will be agricultural tourism; if the aims is to work in farm it will be farm tourism; if the aims is to spend leisure time and use tourism and recreational spaces of rural, it will be recreational tourism; if the aims is to get specific cultural features of places such as customs, indigenous sports and music, it will be cultural tourism and if the aim is pristine nature with all its ecological characteristics it will be ecotourism.

The need for rural recreational spaces:

In tourism industry, the environment (natural or artificial) is not only the context of tourism activities, but it is considered attraction and creates interaction between environment and tourism activity that contains variety of economic, social and administrative effects and consequences.

Since rural attractions are main requirements of rural tourism formation (not sufficient requirements), then combining attractions with other components can shape tourism product in the best form; rural tourism special atmosphere will be created when tourism products can be aligned with other services. In this regard, we need feasibility of rural tourism in order to recognize the product-oriented potential; below concept refers to this matter. 


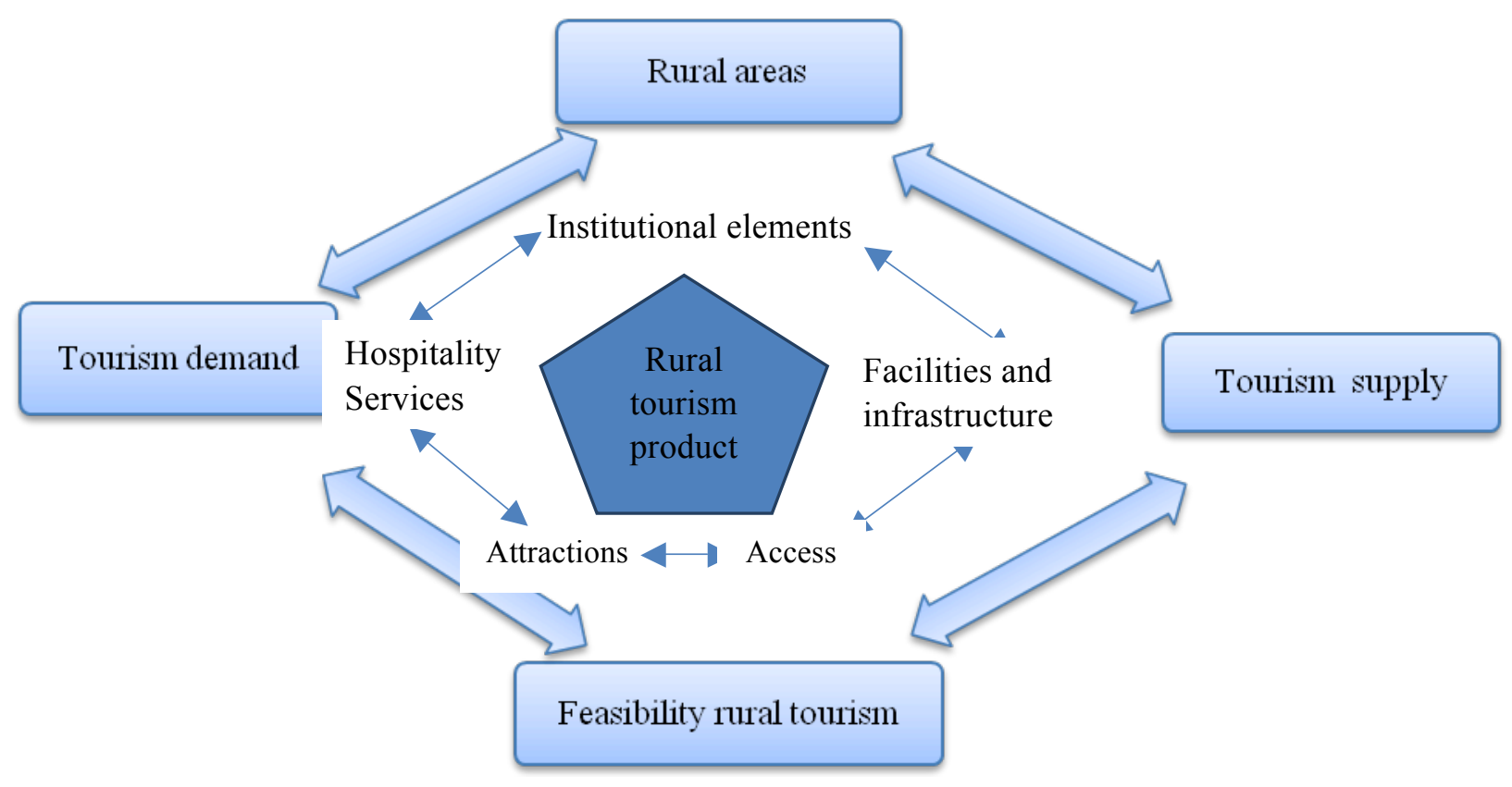

Figure 3: Conceptual model of rural tourism feasibility

According to proposed model, it can be said that five above-mentioned factors can play essential role in creation of rural development document and assessment of village for sustainable development depends on table formation including measurement of these factors and solve them.

Development of tourism infrastructures is often a key factor in growth of this activity. Catering facilities of reception, transportation, yachts harbor, recreational equipment such as tele-cabins and game fields and other tourism activities are infrastructure that are proposed for sustainable development of tourism.

Entertainment capabilities of each village can be increased after development of infrastructures and facilities and due to potential of each country based on its location and leisure - tourist times so that potential facilities are converted to practical facilities.

Since tourism industry is effective on income amount and national income, its development will increase these effects in infrastructure sector and services sector and will play significant role in industry stability. In addition, it will improve and maintain rural valuable areas as well as will design and create hangouts for tourists in order to spend more time in those places.

Tourist resorts or recreational touristic spaces are destinations that provide a wide range of tourism facilities and services and are designed for relaxation or health of clients.

These spaces can be merged and provide a variety of services to customers.

Construction of each recreational and touristic space in villages requires money and manpower in three stages of pre-construction, construction and post-construction; employment in every stage leads to creation of employment opportunities and native income and can save location and future development of village in long term by reimbursement of expenses.

Studies show that each country can attract especial visitors in a particular context and make them his attractions customers. Visitors provide revenues and if they stay more than one day, revenues will 
increase, too. Meanwhile, tourism revenues lead to more revenue, cash flow and ultimately economic prosperity of region.

Awareness of each village values and recreational and touristic attractions creates national interest and pride among local people created and makes them resources guards. Some areas are forgotten over time due to lack of recreational and tourist facilities in attracting tourists. However, using a clear strategy and a detailed analysis we can change desert area or a dry mountain to place with touristic attractions.

In addition, the presence of tourists in village can have negative effects and consequences including ecological, biological and cultural damages. Using appropriate strategies are better for development of rural tourism and support places against damage. Therefore, determining the specific locations with capabilities of recreational-touristic space we can develop regional tourism industry to national tourism and control the process and prevent irreparable damages.

\section{CONCLUSION}

If local community has necessary motivation, financial assistance and technical support in order to build dynamic space and sustain tourism industry it can take advantage of available resources for residential development and offer traditional values. Creating diversity in appropriate spaces with facilities and security for all segments of society can be mentioned in national scale; if these objectives are to be submitted in correct order and in accordance with appropriate program; they can receipt a large number of visitors and foreign tourists. So we can say that revival and preservation of valuable rural areas, concentrated leisure and touristic areas services are important factor in sustainable development of tourism in national and regional scales.

\section{REFERENCES}

Zahedi Asl, Mohammad (2002), Foundations of Social Welfare, Tehran, Allameh Tabatabai University Publication

Zamani Pur, Asadollah (1992) (1371), promotion of agriculture in development process, Birjand, author Qaderi, Ismail (2003), role of rural tourism in sustainable rural development, Ph.D. thesis, University of Tarbiat Modarres

Griffin, Keith and Terry Mac Kennelly (1996), realization of human development strategy, translated by Gholam Reza Khajehpour, Tehran, National Library of Social Security

\section{Latin Refrences}

Dann,GMS, 1999, Theoreticallssues for Tourism's future development

Holland,j, Burain, M.(2003), Tourism in Poor Rural Areas, Diversifying the product and expanding the benefits in rural, paper No.12

Lane, B .(1994). What is rural tourism ? Journal of sustainable tourism 2 ( 1-2 )7-21. 